\title{
Analysis and Control of Single Phase Grid Connected Modular Multilevel Converter in Per Unit
}

\author{
Elif Beyhan Çerçi ${ }^{* *}$ (i), Eyup Akpınar ${ }^{1}$ (i) \\ ${ }^{1}$ Dokuz Eylül University, Department of Electrical and Electronics Engineering, Turkey
}

\begin{abstract}
In this paper, a mathematical model and control methods of a modular multilevel converter are examined in per unit. Some control algorithms, like a sorting algorithm, circulating current control, proportional resonant controller and pulse width modulation techniques which are applicable on this converter are investigated. The average value model is used in per unit for the converter and it is combined with circulating current control method and propotional resonant current controller to suppress the second harmonic component in the circulating current. The effect of the circulating current harmonics on the resonance frequency is investigated. A Matlab/Simulink model is prepared for the simulation of converter modeled on the approach of the average value model and the results are generated from the simulation and they are discussed.
\end{abstract}

Keywords: Modular multilevel converter, average value model, circulating current control, resonance frequency, per unit

\section{INTRODUCTION}

The modular multilevel converters (MMC) has an important impact on the design of $\mathrm{AC} / \mathrm{DC}$ conversion in high power applications. It can be manufactured easier for high power application under medium and high voltage levels due to its modular structure. The low voltage rated solid state devices, capacitors and inductances are used in this cascade configuration [1]. Its main structure and control strategies presented firstly in [2]-[4] and opened an important research area in the high voltage direct current transmission. While these converters are operated as the front end grid connected rectifiers, they can be operated as the inverter for the torque and speed control of three-phase induction and synchronous motors. In order to approach the ideal rectification and inversion features, the optimizing control algorithms, some sorting algorithms [5] and PWM modulations techniques are suggested [6].

The average value model presented in [7-9] is analyzed in the per unit system in this paper in order to specify the proper inductance and capacitor values independently to power rating of the converter. The resonance frequency is analysed depending on the circulating current harmonics in [10]. The approach in [11] presents a technique for selecting the arm inductance and module capacitance based on the power capacity of converter and resonance frequency. The selection of these parameters can be carried out independent to the power rating of the converter if the per unit sytem is used.

Here, the average value model of the converter in per unit is combined with the proportional resonant controller employed for the circulating current of the grid connected three-phase modular multi level converter. The rest of the paper is organized as follows: The section 2 covers the operation principles, mathematical model and summary of control methods. The section 3 gives the Matlab simulation results, the section 4 is dedicated for the resonance frequency and the section 5 is the conclusion.

\section{MODULAR MULTILEVEL CONVERTER}

\subsection{Operation Principles}

The modular multilevel converters consist of numbers of submodules. Each leg has two arms called as upper and lower arms. Each arms has N number of submodules. This number is determined depending on the submodule voltage rating and the voltage rating of the converter. The number of submodules in the upper and lower arms in each phase leg must be equal. Its modular structure allows to increase or decrease the number of modules for critical loads in a faulty condition.

All arms also have a small inductor and a resistor to limit the circulating current. The selection of these parameters are also depending on the instantaneous power balance in the 
specified range of capacitor voltage ripple and the constraint on the resonance frequency [11].

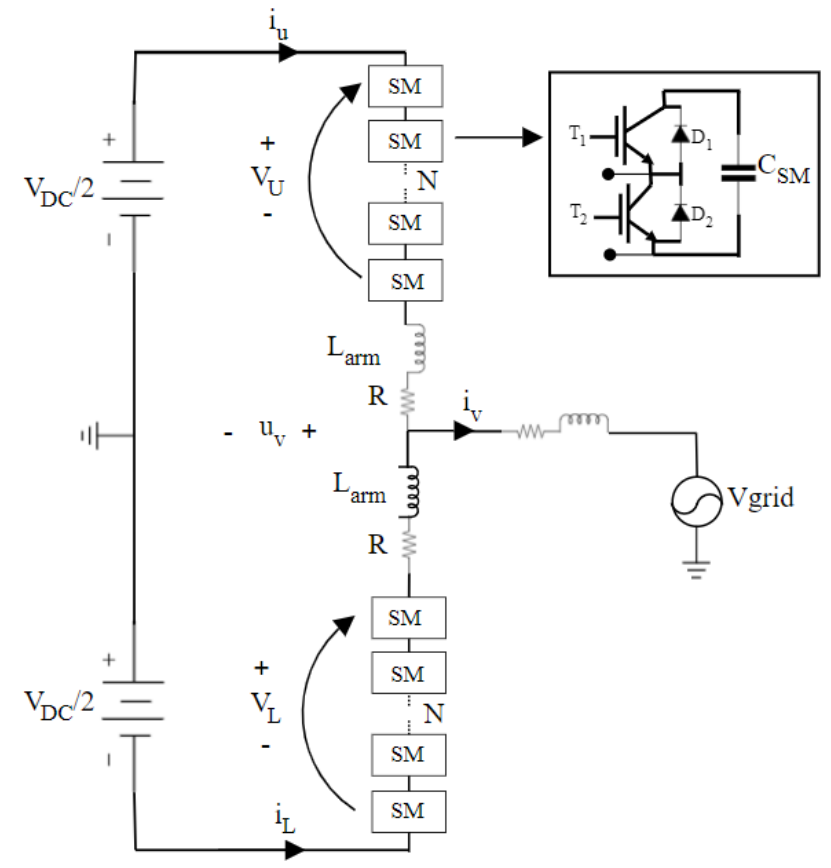

Figure 1. The basic modular structure of MMC

In this paper, a cascaded half bridge (CHB) topology will be taken into account as a submodule structure. The CHB structure is one of the commonly used topologies in the MMCs. It contains the half bridge submodules with two IGBT switches, two parallel diodes and one capacitor that is parallel to the solid state devices as shown in the figure 1 . The capacitor voltage changes according to the direction of the current and the decisions on the selection of the switching status are made in order to keep the voltage variation across the capacitor in the specified range. There are four possible switching status as it is shown in figure 2.

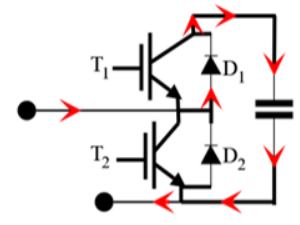

(a)

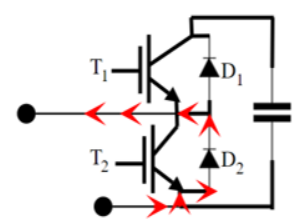

(c)

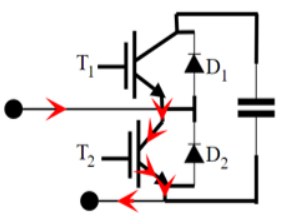

(b)

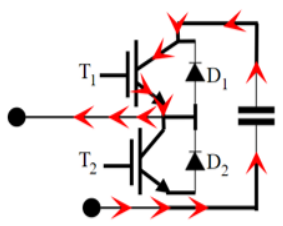

(d)
Figure 2. Submodule current states

DC-link capacitor behaves like a voltage source. Some of them in the arm are inserted and the others are bypassed to generate desired voltage level. The IGBTs T1 and T2 work in a complementary switching that is basis of the PWM application. When T1 is on, T2 should be off to avoid a short circuits across the capacitor. Due to the positive or negative current directions, the control algorithm selects the submodules (SMs) which the capacitor will be charged or dischar- ged. When the $\mathrm{T} 1$ is on and $\mathrm{T} 2$ is off as shown in figure a, the positive current directly flows through the capacitor and the capacitor will be charged. The SM is bypassed as shown in figures $2 \mathrm{~b}$ and $2 \mathrm{c}$ keeping the currents in positive or negative cycles. When the T1 is on and T2 is off, the current flows through the capacitor leaving the positive terminal as shown in figure $2 \mathrm{~d}$ and the capacitor is discharged.

\subsection{Mathematical Model}

The converter has $\mathrm{N}$ submodules in each arm and capacitance value of this submodules is $\mathrm{C}_{\mathrm{SM}}$. The total series connected capacitors is computed from (1).

$$
C_{A r m}=\frac{C_{S M}}{N}
$$

The arm effective capacitance depends on the modulation (insertion) index m;

$$
\begin{aligned}
& n_{U}=\frac{1}{2}(1-m \cos (\omega t)) \\
& n_{L}=\frac{1}{2}(1+m \cos (\omega t)) \\
& C_{\text {eff. }}=\frac{C_{A r m}}{n(t)}
\end{aligned}
$$

The modulation index dedicates the number of inserted capacitors or in the correct form submodules. $n(t)=1$ means that all modules in the arm are inserted, otherwise while $\mathrm{n}(\mathrm{t})=0$ all modules are bypassed. Equal voltage regulation is ensured by the selection of modulation index. According to current direction and capacitance values, the converter is controlled. If the current direction is on charging way, the lowest charged SM will be inserted and the highest will be bypassed. For the opposite way, to discharge the highest

capacitor, the highest charged capacitor will be inserted and the others bypassed. It depends on the system requirement [8].

All control algorithms aim to set all capacitor voltages equal. Thus, $\mathrm{V}_{\mathrm{CU}}$ and $\mathrm{V}_{\mathrm{CL}}$ are the upper and lower arm voltages are controlled. The inserted voltage by the arm becomes sum of all active submodules voltages and expressed as;

$$
\begin{aligned}
& V_{U}=n_{U} V_{C U}^{\Sigma} \\
& V_{L}=n_{L} V_{C L}^{\Sigma}
\end{aligned}
$$

In the leg of one phase, as it is shown in the figure 1 , the sum of upper and lower arm current gives the phase output current. The circulating current $i_{\text {diff }}$ occurs due to difference of the arm currents.

$$
\begin{aligned}
& i_{v}=i_{U}+i_{L} \\
& i_{d i f f}=\frac{i_{U}-i_{L}}{2} \\
& i_{U}=\frac{i_{v}}{2}+i_{\text {diff }} \\
& i_{L}=\frac{i_{v}}{2}-i_{\text {diff }}
\end{aligned}
$$


If we write current equations in terms of voltages,

$$
\begin{aligned}
& i_{U}=\frac{C_{A r m} d\left(V_{C U}^{\Sigma}\right)}{n_{U} d t} \\
& i_{L}=\frac{C_{A r m} d\left(V_{C L}^{\Sigma}\right)}{n_{L} d t}
\end{aligned}
$$

To obtain differential equations for upper and lower arm voltages,

$$
\begin{aligned}
& \frac{d\left(V_{C U}^{\Sigma}\right)}{d t}=\frac{n_{u}}{C_{A r m}} i_{d i f f}+\frac{n_{u}}{2 C_{A r m}} i_{v} \\
& \frac{d\left(V_{C L}^{\Sigma}\right)}{d t}=\frac{n_{L}}{C_{A r m}} i_{d i f f}-\frac{n_{L}}{2 C_{A r m}} i_{v}
\end{aligned}
$$

The upper and lower arm currents can be expressed as follows;

$$
\begin{aligned}
& i_{U}=I_{D C}+\frac{I_{M}}{2} \sin (\omega t)+I_{\text {diff }} \sin (2 \omega t) \\
& i_{L}=-I_{D C}+\frac{I_{M}}{2} \sin (\omega t)-I_{\text {diff }} \sin (2 \omega t)
\end{aligned}
$$

The mathematical model can be simplified by using Kirchhoff's voltage law from the figure (1)

$$
\begin{aligned}
& V_{D C} / 2-V_{U}-L_{a r m} \frac{d i_{U}}{d t}-R i_{U}=u_{v} \\
& -V_{D C} / 2+V_{L}-L_{a r m} \frac{d i_{L}}{d t}-R i_{L}=u_{v}
\end{aligned}
$$

Subtracting equations (17) and (18), the following relation is obtained;

$$
V_{D C}-\left(V_{U}+V_{L}\right)=L_{a r m} \frac{d}{d t}\left(i_{U}-i_{L}\right)+R\left(i_{U}-i_{L}\right)
$$

If the equation (8) is substituted into (19);

$$
\begin{aligned}
& V_{D C}-\left(V_{U}+V_{L}\right)=2 L_{a r m} \frac{d i_{d i f f}}{d t}+2 R i_{d i f f} \\
& \frac{d i_{d i f}}{d t}=\frac{V_{D C}}{2 L_{a r m}}-\frac{R i_{d i f}}{L_{a r m}}-\frac{n_{U} V_{C U}^{\Sigma}}{2 L_{a r m}}-\frac{n_{L} V_{C L}^{\Sigma}}{2 L_{a r m}}
\end{aligned}
$$

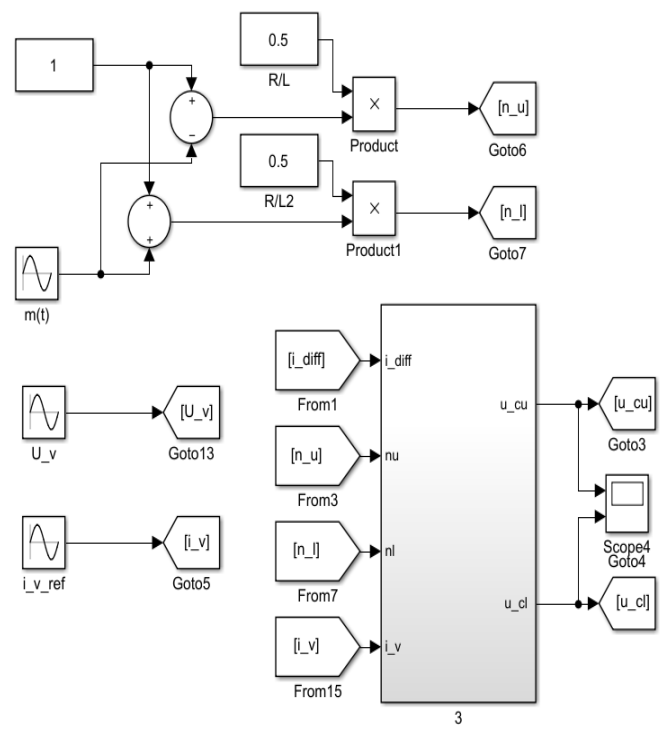

The dynamic average value model is obtained as follows,

$$
\frac{d}{d t}\left[\begin{array}{l}
i_{i d f f} \\
V_{C U}^{\Sigma} \\
V_{C L}^{\Sigma}
\end{array}\right]=\left[\begin{array}{ccc}
-\frac{R}{L} & -\frac{n_{u}}{2 L} & -\frac{n_{L}}{2 L} \\
\frac{n_{u}}{C_{a r m}} & 0 & 0 \\
\frac{n_{L}}{C_{a r m}} & 0 & 0
\end{array}\right]\left[\begin{array}{l}
i_{d i f} \\
V_{C U}^{\Sigma} \\
V_{C L}^{\Sigma}
\end{array}\right]+\left[\begin{array}{c}
\frac{V_{D C}}{2 L} \\
\frac{n_{u v} i_{v}}{2 C_{a r m}} \\
-\frac{n_{L} i_{v}}{2 C_{a r m}}
\end{array}\right]
$$

\subsection{Control Methods}

The current and voltage control methods eliminate the harmonic components of circulating current and voltage ripple on the capacitors. The pulse width modulation technique is the most commonly used method to control voltage and currents in the converter. The comparison of triangular wave with sinusoidal reference generates the gate signal that is either 1 or 0 in time. For the MMC control, there are two different PWM techniques, namely the level-shifted or the phase-shifted. In addition to them, the nearest level modulation and the sorting algorithm are also a very useful and popular methods to keep submodule voltages in the specified ripple range. The circulating current control is usually carried out by using the proportional resonance technique.

\section{MATLAB MODELS AND THE RESULTS OF SIMULATIONS}

\subsection{Open Loop Model}

The average value model (22) consisting of the dynamic equations is to evaluate circulating current and upper and lower arm voltages as it is given in figure 3 with Matlab blocks. Due to the open loop structure, the modulation indexes given in equations (2) and (3) are used. First block and third block evaluate the differential current and the arm voltages.

The actual system parameters are the grid voltage $U_{v}=50$ $\sin (w t)$, the grid current $I_{v}=10 \sin (w t+\omega), V_{D C}=200 V$, $\mathrm{C}_{\text {arm }}=5 \mathrm{mF}, \mathrm{L}=3 \mathrm{mH}, \mathrm{R}=0.1 \Omega$ and the grid frequency is $50 \mathrm{~Hz}$.

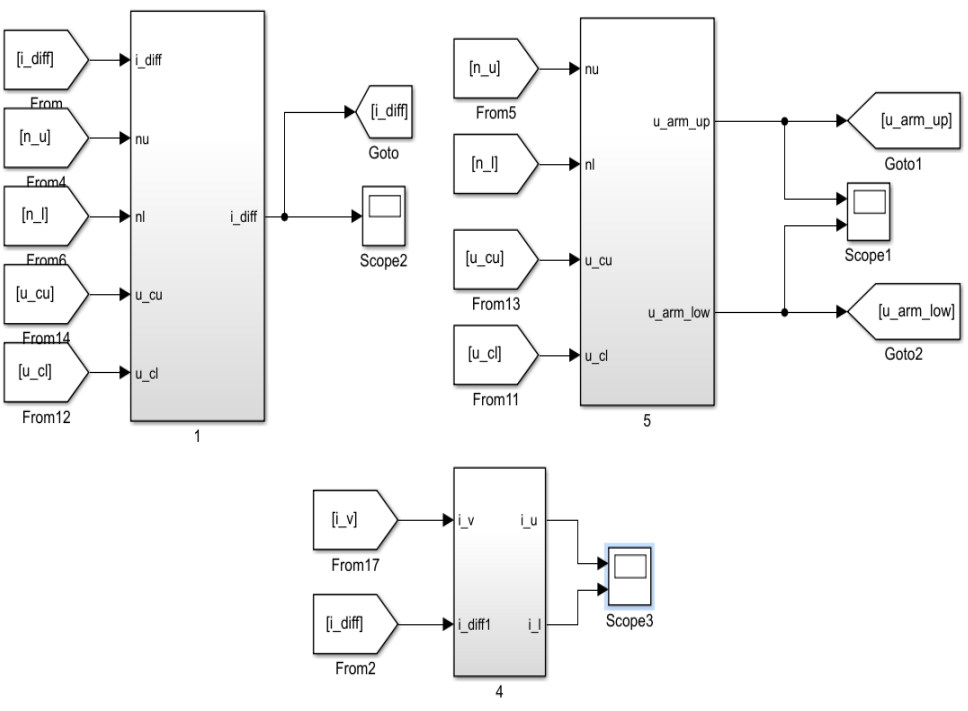

Figure 3. MATLAB blocks of open loop model 

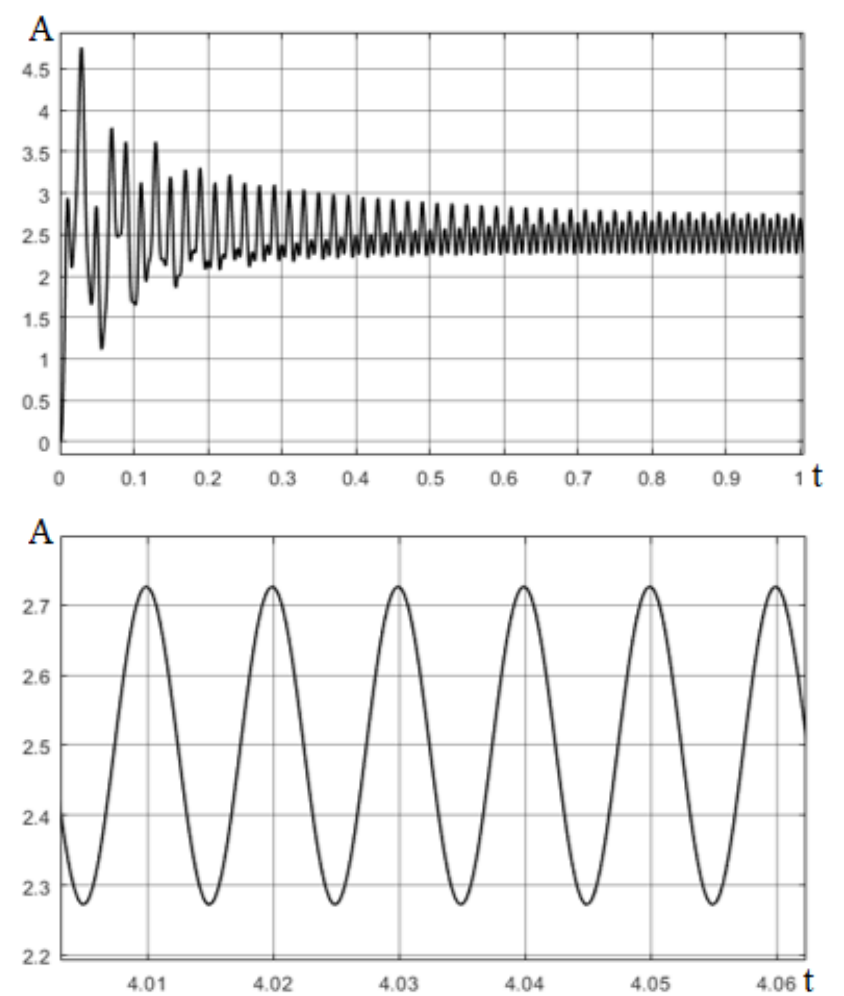

Figure 4. Differential current envelope and its steady-state variation in time

As seen from the figure 4, due to the lack of control loop, the steady state value of differential current shows a large magnitude in percent. The arm capacitor voltage shown in figure 5 has a large voltage ripple. However, the differential current and the arm voltage settle down a stable level after the starting transients. The arm capacitor voltages of the submodules are equal at the steady state operation.
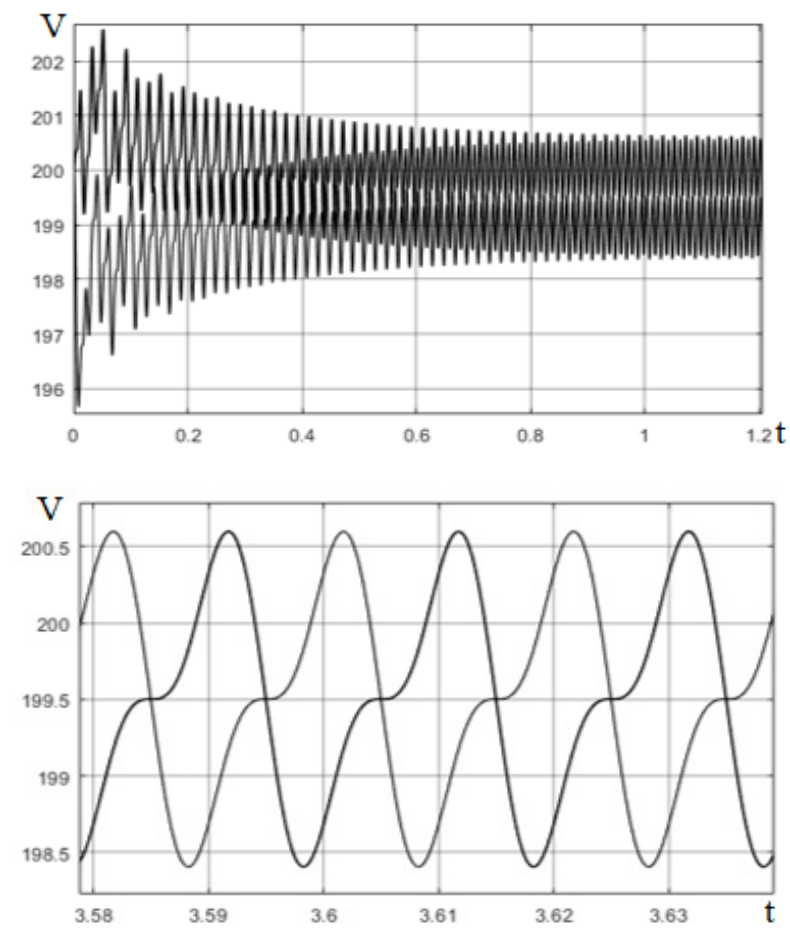

Figure 5. Arm capacitor voltages and its steady-state variation in time

\section{Per Unit Model}

The converter model is solved in per unit in order to eliminate the effects of converter voltage and power capacity on the selection of inductance and capacitor values. The base values for the voltage and current are $\mathrm{U}_{\text {base }}=50 \mathrm{~V}$ and $\mathrm{I}_{\text {base }}$ $=10 \mathrm{~A}$. The rest of the base values are computed by using these two base values.

$$
\begin{aligned}
& S_{\text {base }}=V_{\text {base }} I_{\text {base }} \\
& Z_{\text {base }}=V_{\text {base }} / I_{\text {base }} \\
& R_{p u}=\frac{R}{Z_{\text {base }}} \\
& L_{p u}=\frac{L}{Z_{\text {base }}} \\
& C_{p u}=C \cdot Z_{\text {base }}
\end{aligned}
$$

The system parameters in per unit are $\mathrm{V}_{\mathrm{dc}}=4 \mathrm{pu}, \mathrm{R}_{\mathrm{pu}}=$ $0.02 \mathrm{pu}, \mathrm{L}_{\mathrm{pu}}=0.006 \mathrm{pu}$ and $\mathrm{C}_{\mathrm{pu}}=0.025 \mathrm{pu}$

\subsection{Circulating Current Control}

The control method shown in figure 6, is used to suppress the ac component (second harmonic) of the circulating current. This current is defined as $i_{\text {diff }}$ and it is computed from the equation (8). A low pass filter is used to extract the DC component. The only ac part remains after subtracting the dc component passed. Then the error between the ac part and reference value is calculated and passed through the proportional resonant controller (PR) [7, 12].

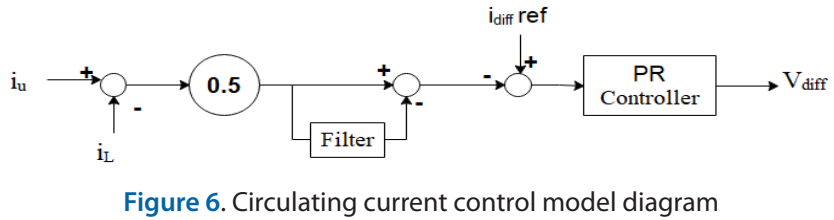

The output of circulating current suppression method in figure 6 gives the differential voltage reference and it is taken into account in the converter reference voltage. Implementing a PR controller can eliminate steady-state error via its infinite gain. Its transfer function is given in (28)

$$
G_{\mathrm{PR}}=K_{p}+\frac{K_{i} s}{s^{2}+w_{0}^{2}}
$$

The results show that this method is successful to suppress the circulating current and the transients. The starting transients damp out in less then one second. The suitable $\mathrm{K}_{\mathrm{p}}$ and $\mathrm{K}_{\mathrm{i}}$ parameters are selected via Matlab optimization tool [13]. 

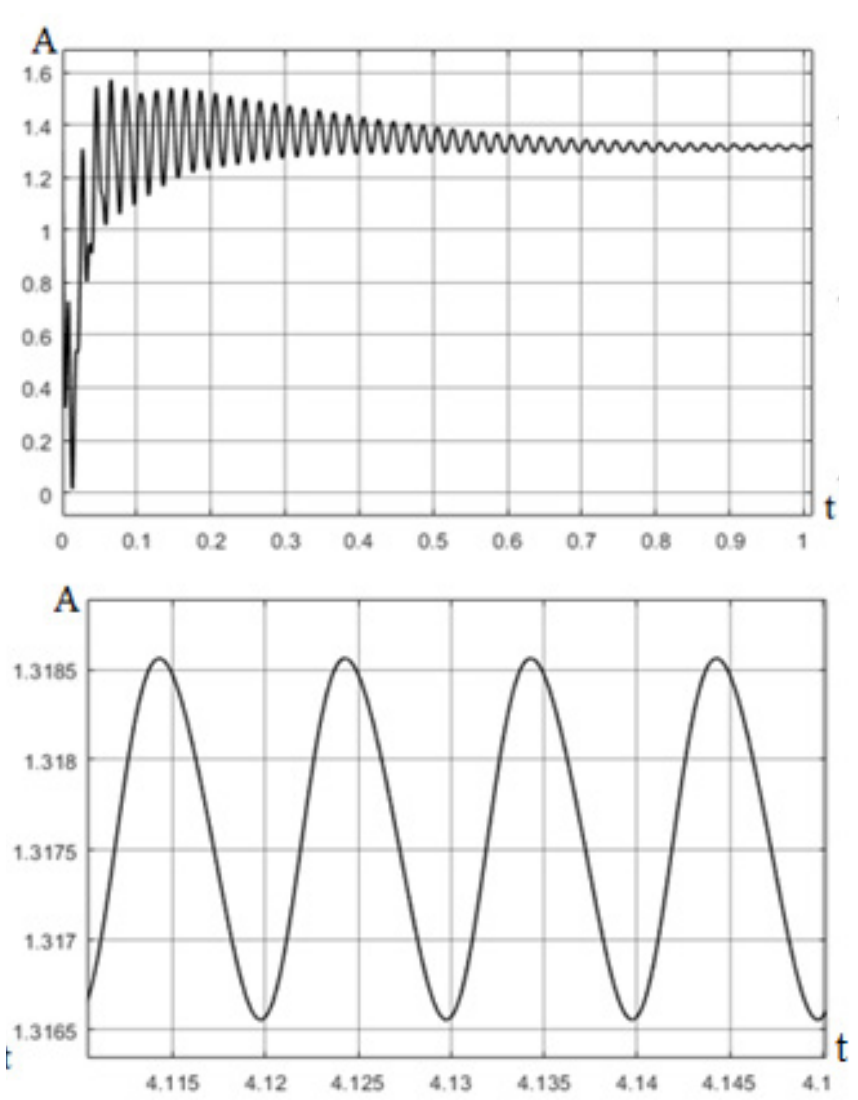

Figure 7. Circulating current and its steady state variation in time

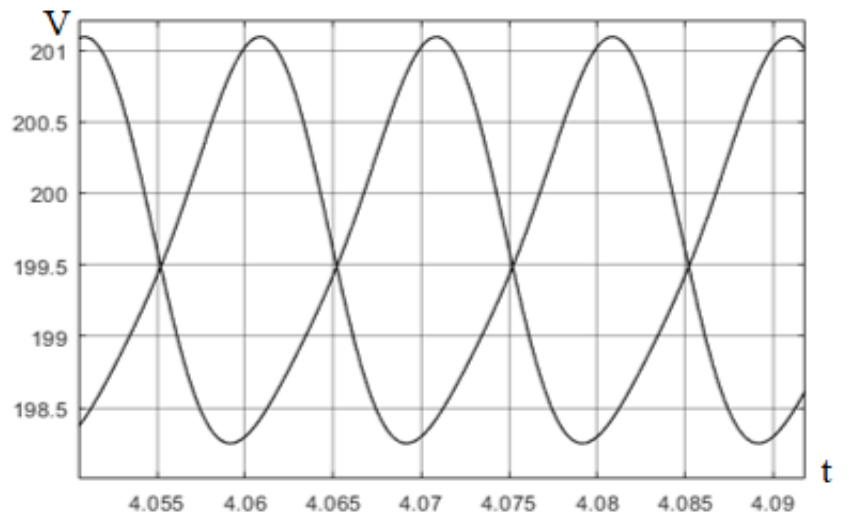

(a)

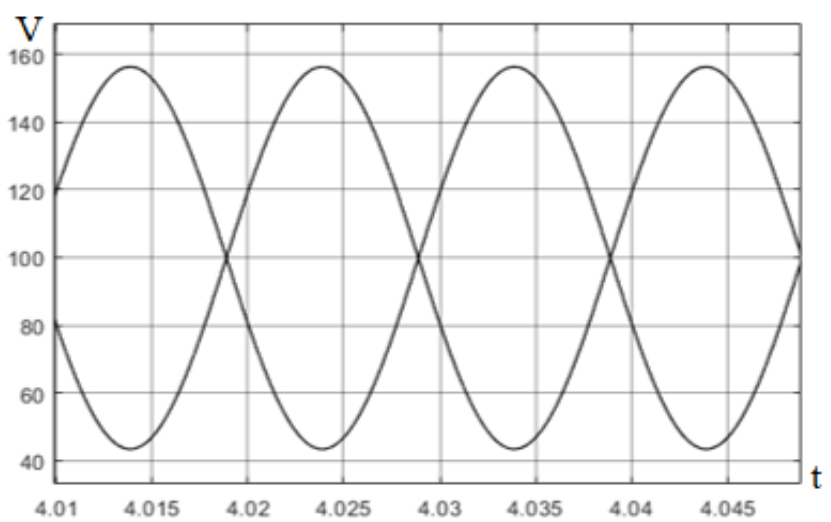

(b)

Figure 8. (a) The capacitor voltages and (b) The arm voltages

\section{RESONANANCE FREQUENCY}

The resonance frequency in (29) affects the magnitude of circulating current [10].

$$
\omega_{r}=\sqrt{\frac{N}{L_{a r m} C_{S M}}} \sqrt{\frac{2\left(n^{2}-1\right)+m^{2} n^{2}}{8 n^{2}\left(n^{2}-1\right)}}
$$

The highest resonant frequency is generated when modulation index $(m)$ is equal to 1 and the second harmonic $(n=2)$ is selected.

$$
\mathrm{w}_{r}=\sqrt{\frac{5}{48} \frac{1}{L_{\text {arm }} C_{\text {arm }}}}
$$

According to the equation (30), the critical value for the system is $13.27 \mathrm{~Hz}$. To observe the effect of resonance condition on the circulating current, the average value model without the closed loop control is solved at the grid frequency changed from $5 \mathrm{~Hz}$ to $70 \mathrm{~Hz}$. The results of the simulation at these frequencies are given in figure 9 as the graphic.

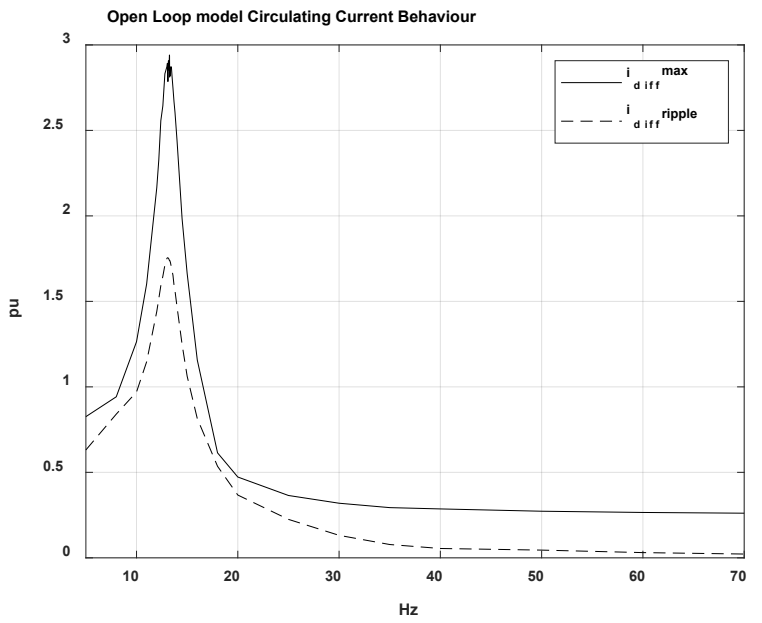

Figure 9. Change of differential current based on frequency in pu.

The solid line indicates the peak to peak ripple magnitude of the circulating current and the dashed line is peak amplitude in per unit. The system power loss is high around resonant frequency. Figure 10 shows the circulating current variation at different supply voltage frequencies (covering the resonance frequency) if the PR controller is enabled. The resonance is suppressed since the second harmonic is eliminated [13]. 


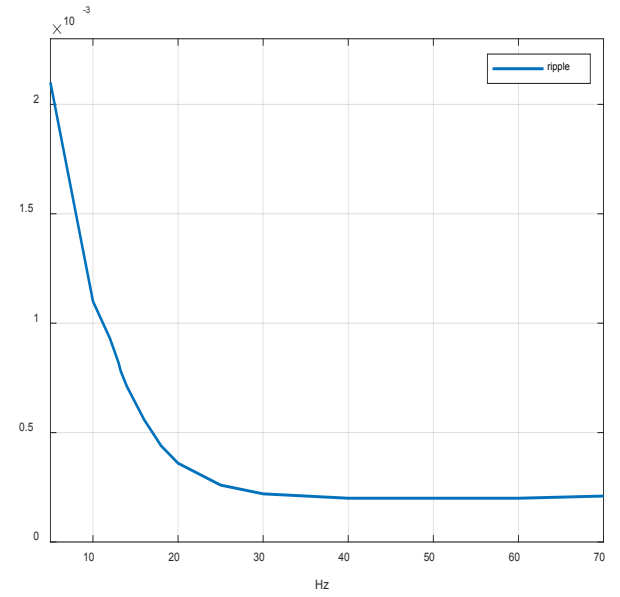

(a)

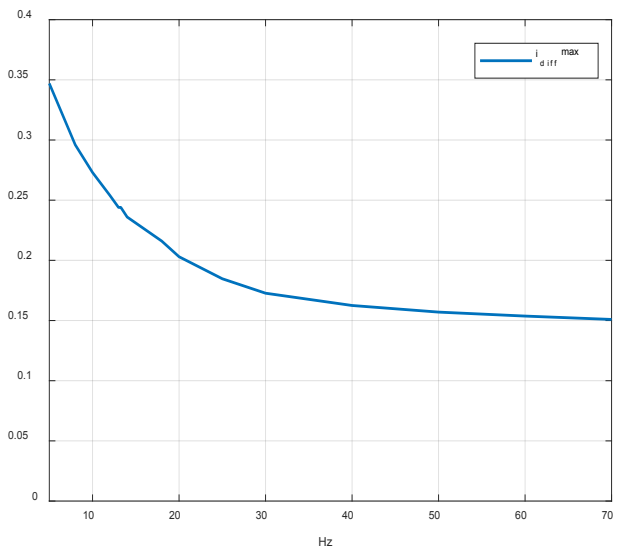

(b)

Figure 10. Change of differential current (a) ripple (b) peak amplitude in per unit

\section{CONCLUSION}

In this paper, the average value model of the $\mathrm{MMC}$ in per unit is used together with the circulating current control. The control of the circulating current is based on the PR controller and the system is analyzed in Matlab. The results show that the controller is significantly effective for suppressing the circulating current. This model is good enough to identify the resonance frequency depending on the harmonic components of circulating current and the modulation index. The results indicate that the resonance directly affects the magnitude of circulating current. The suppression of harmonic current components of the circulating current avoids the resonance in the system.

\section{REFERENCES}

[1] Asimakopoulos P. (2013) "Design And Control Of Modular Multilevel Converter In An Active Front End Application", CERN Thesis $-2013-274$, pp. 2-3

[2] Lescinar A. And Marquardt R. (2003) "An Innovative Modular Multilevel Converter Topology Suitable For A Wide Power Range", IEEE Bologna Power Tech Conference Proceedings, June 23 - 26, Bologna, Italy; vol. 3, p 6

[3] Lescinar A. And Marquardt R. (2003) "A New Modular Voltage Source Inverter Topology", In Proceedings Of The European Power
Electronics Conference (EPE), Sep 2 - 4, Toules, France; pp. 1 - 10

[4] Marquardt R. And Lescinar A. (2004) "New Consept For High Voltage - Modular Multilevel Converter", IEEE PESC, June 20 - 25,Achen, Germany.

[5] Glinka M. And Marquardt R. (2003) "A New Single PhaseAC/AC Multilevel Converter For Traction Vehicles Operating On AC Line Voltage", Power Tech Conference Proceedings IEEE,Bologna, vol 3 pp 6

[6] Hagiwara M., Maeda R. And Akagi H. (2011) "Control And Analysis Of The Modular Multilevel Cascade Converter Based On Double-Star Chopper- Cells (MMCC-DSCC) ", Power Electronics IEEE Transactions, vol.26, pp $1649-1658$

[7] Jinke L., Konstantinou G., Wickramasinghe R. H., Pou J., Wu X. And Jin X. (2018) "Impact Of Circulating Current Control In Capacitor Voltage Ripples Of Modular Multilevel Converters Under Grid Imbalances" IEEE Transaction On Power Delivery, vol. 33, 2018 June

[8] Antonopoulos A., Angquist L. And Nee H. (2009) " On Dynamics And Voltage Control Of The Modular Multilevel Converter ", Power Electronics and Applications, 2009. EPE'09. 13th European Conference,

[9] Teodorescu R. And Zarri L. (2012) "Modular Multi-Level Converter:Modeling, Simulation and Control in Steady State and Dynamic Conditions", Department of Energy Technology, AalborgUniversity,Denmark https://projekter.aau.dk/projekter/files/63645060/THESISrevFinale.pdf

[10] [10] Ilves K., Antonopoulos A., Norgga S. And Nee HP. (2012) "Steady State Analysis Of Interaction Between Harmonic Components Of Arm And Line Quantities Of Modular Multilevel Converters

[11] Ilves K., Antonopoulos A., Norgga S., Harnefors L. And Nee HP. (2014) " On Energy Storage Requirements In Modular Multilevel Converters

[12] Wang J., Liang J., Wang C. And Dong X. (2017) "Circulating current suppression for MMC-HVDC under unbalanced grid conditions", IEEE Industry Applications, vol.53, pp. 3250 - 3258

[13] Çerçi E. B. , Analysis and Control of Single Phase Grid Connected Modular Multilevel Converter, M.Sc Thesis, Dokuz Eylul University, 2019 